Check for updates

Cite this: RSC Adv., 2018, 8, 38765

\title{
Sulfate radical oxidation combined with iron flocculation for upgrading biological effluent of coking wastewater $\dagger$
}

\author{
Zhichun Zhang, ${ }^{\text {ab }}$ Xiuping Yue, ${ }^{\text {a }}$ Yanqing Duan, ${ }^{a}$ Xiao Zhang, ${ }^{a}$ Yanjuan Gao, ${ }^{a}$ \\ Rao Zhuc and Xia Cui ${ }^{\text {d }}$
}

\begin{abstract}
Because the components of the coking wastewater was biologically toxic and hence inhibit the actions of microorganisms in conventional biological treatment processes, the biological effluent of coking wastewater (BECW) still remains much recalcitrant pollutants. In the current work, we set out to explore the feasibility of using a proposed advanced oxidation method, involving the persulfate-activated zerovalent iron system (PS/ZVI), to realize a deep treatment of BECW. The efficiency levels at which sulfate radical oxidation combined with iron flocculation removed pollutants, specifically TOC, phenolic compounds (PCs), cyanide, and suspended solids (SSs), as well as removing colour were investigated in batch tests. Increasing the persulfate concentration generally resulted in improved pollutant removal, with maximum removal efficiency levels of 58.5\%, 68.4\%, 61\% 99.9\% and $91.04 \%$ for TOC, PCs, SS, cyanide and colour, respectively. Note that the coexisting inorganic ions $\mathrm{CO}_{3}{ }^{2-}$ and $\mathrm{HCO}_{3}{ }^{-}$were strong competitors of the radical consumption of TOC, but this interference was eliminated by adjusting the $\mathrm{pH}$ to 4.5. Also, flocculation of the generated $\mathrm{Fe}^{3+}$ ions from the radical reaction significantly enhanced SS removal. GC-MS analysis showed that the compositional diversity of the BECW decreased after oxidation. Meanwhile its biodegradability increased, indicating less bio-toxicity reaching the natural water body. This study suggests that the PS/ZVI system may be an alternative safer and more efficient method than Fenton's method for carrying out an advanced treatment of coking wastewater.
\end{abstract}

Received 30th September 2018 Accepted 3rd November 2018

DOI: $10.1039 / c 8 r a 08134 d$

rsc.li/rsc-advances $\left.300 \mathrm{mg} \mathrm{L}^{-1} \mathrm{COD}^{3,4}\right)$ during biological processes, the effluent still contains large complex pollutants including polycyclic aromatic hydrocarbons (PAHs), cyanide, phenolic compounds (PCs), and nitrogen heterocyclic compounds (NHCs), which may seriously pollute the air, surface water, groundwater, and soil around the source factory, and may even endanger the safety of human beings., ${ }^{5,6}$ PAHs, which have been identified as highly carcinogenic chemicals by the International Agency for Research on Cancer (IARC), can induce human oxidative stress and consequent metabolic and neuropsychological disorders. ${ }^{6}$ NHCs that exist in the aquatic environment have a higher eco-toxic effect on microorganisms. ${ }^{7}$ The half lethal dose $\left(\mathrm{LD}_{50}\right)$ of pyridine, indole, and quinoline have been measured to be 891,1000 , and $460 \mathrm{mg} \mathrm{kg}^{-1}$, respectively. ${ }^{8}$ Cyanide, a constituent of acute toxic inorganics ${ }^{9}$ such as potassium cyanide (with a lethal dose (LD) of $506.4 \mathrm{mg} \mathrm{kg}^{-1}$ ), can enter the air rapidly as a result of volatilization..$^{10}$ Consequently, to avoid diffusion and accumulation of the mentioned pollutants, advanced treatment of effluent from biological processes of coking wastewater to achieve minimal impact on the receiving ecosystems has become an important goal.

Advanced oxidation processes (AOPs) form an effective method to further reduce the concentration of bio-toxic organics in BECW for preventing damage to aquatic 
ecosystems. Studies on the removal characteristics of the AOPs have been reported in the literature, including Fenton's oxidation, ${ }^{11,12}$ ozone oxidation, ${ }^{13,14}$ absorption, ${ }^{15}$ and a combination of these methods. However, ozone oxidation consumes a lot of energy, ${ }^{16}$ and the Fenton and Fenton-like methods can produce a large amount of chemical sludge. ${ }^{\mathbf{1 3 , 1 7 , 1 8}}$ Hence, the development of an alternative advanced treatment of coking wastewater has been urgently sought. In recent years, a promising oxidation approach using the sulfate radical $\left(\mathrm{SO}_{4}{ }^{-\bullet}\right)$ with an oxidation potential of 2.5-3.1 eV has been proposed. ${ }^{19}$ And this approach has outperformed other approaches due to its extensive applicability to most organics, diversified activation (e.g., transition metals, alkali, and heat), and moderate reaction conditions. ${ }^{\mathbf{1 9 , 2 0}}$

Since performance of $\mathrm{SO}_{4}{ }^{-\cdot}$ on $\mathrm{BECW}$ is relatively unexplored, especially for actual wastewater, we set out to investigate the feasibility of using the sulfate radical for the advanced treatment of BECW. Given the quenching effect by $\mathrm{Fe}^{2+}$, the zero-valent iron (ZVI) in the solid state was used as an activator to promote radical release. Also, special attention was focused on the effect of the concentration of $\mathrm{Na}_{2} \mathrm{~S}_{2} \mathrm{O}_{8}$ on the change of total organic carbon (TOC), phenol compounds (PCs), cyanide and colour in the BECW. Due to the generated $\mathrm{Fe}^{3+}$ in flocculation and precipitation, the removal of the suspended solids (SS) was also investigated. In addition, to gain deep insight into the oxidation process, the diversity of the composition of the BECW before and after the oxidation reaction was evaluated by using a gas chromatograph-mass spectrometer (GC/MS) and its biodegradability was assessed by determining the ratio of the biological oxygen demand (BOD) to the chemical oxygen demand (COD). This research is expected to provide a new practical method for the comprehensive treatment of actual industrial wastewater.

\section{Materials and methods}

\subsection{Raw wastewater}

Raw wastewater was obtained from the effluent of the secondary sedimentation tank of the coking wastewater treatment plant in Jiaocheng City, Shanxi Province, China. The wastewater was subjected to centrifugation at $8000 \mathrm{rpm}$ for $1 \mathrm{~h}$, and the resulting supernatant was packed and stored at $4{ }^{\circ} \mathrm{C}$ in a refrigerator until radical oxidation tests were performed. The values of various characteristics of the raw water are listed in Table 1.

\subsection{Materials}

The basic chemical reagents used, including zero-valent iron (ZVI, $\left.\mathrm{Fe}^{0}\right)$, sodium persulfate $\left(\mathrm{Na}_{2} \mathrm{~S}_{2} \mathrm{O}_{8}\right)$, barium chloride $\left(\mathrm{BaCl}_{2}\right)$, sodium hydroxide $(\mathrm{NaOH})$, and sodium sulfide $\left(\mathrm{Na}_{2} \mathrm{~S}\right)$, were of analytic grade. The chromatographically pure reagents used were methylene chloride $\left(\mathrm{CH}_{2} \mathrm{Cl}_{2}\right)$ and methanol $\left(\mathrm{CH}_{4} \mathrm{O}\right)$. All of these reagents were purchased from the Shanxi Xinhua Chemical Factory, China. Neodymium magnets were purchased from the Shanghai Yinghao Magnetic Industry Co. LTD., China. Water was deionized by using an Aquelix 5 water system (Millipore Corp., Bedford, MA, USA).

\subsection{Batch experiments design}

Special attention was focussed on the concentration of $\mathrm{Na}_{2} \mathrm{~S}_{2} \mathrm{O}_{8}$ and the state of ZVI in the experimental design, since these two factors were of great importance to the oxidation process, and could affect the release of sulfate radicals that attack the organics. As for the $\mathrm{Na}_{2} \mathrm{~S}_{2} \mathrm{O}_{8}$ concentration, four different mass concentration ratios of $\mathrm{Na}_{2} \mathrm{~S}_{2} \mathrm{O}_{8}$ to COD, namely $1: 2,1: 4,1: 6$, and $1: 10$, respectively, were investigated. $\mathrm{Fe}^{2+}$ was usually used as a potent activator of $\mathrm{Na}_{2} \mathrm{~S}_{2} \mathrm{O}_{8}$ to release sulfate radical and initiate the oxidation process. However, if there is an excess $\mathrm{Fe}^{2+}$ in the solution, the free radicals can be quenched, resulting in an inhibition of the oxidation. ${ }^{21}$ Thus, ZVI used in this study was in the solid state, which ensured a slow release of $\mathrm{Fe}^{2+}$ ions with a lower likelihood of quenching. The specific reaction process is given in eqn (1)-(3). ${ }^{22}$

$$
\begin{gathered}
\mathrm{Fe}^{0} \rightarrow \mathrm{Fe}^{2+}+\mathrm{e}^{-} \\
\mathrm{Fe}^{3+}+\mathrm{e}^{-} \rightarrow \mathrm{Fe}^{2+} \\
\mathrm{S}_{2} \mathrm{O}_{8}{ }^{2-}+\mathrm{Fe}^{2+} \rightarrow \mathrm{SO}_{4}{ }^{--}+\mathrm{SO}_{4}{ }^{2-}+\mathrm{Fe}^{3+}
\end{gathered}
$$

A volume of $500 \mathrm{~mL}$ of BECW was added to a $1 \mathrm{~L}$ beaker, and $\mathrm{Na}_{2} \mathrm{~S}_{2} \mathrm{O}_{8}$ was added according to the mass concentration ratio of COD to $\mathrm{Na}_{2} \mathrm{~S}_{2} \mathrm{O}_{8}$. Then the reaction was activated by the addition of a certain amount of ZVI subjected to stirring at a speed of $300 \mathrm{rpm}$ using a magnetic water bath. The experiments were operated at room temperature, specifically at $25 \pm 0.5{ }^{\circ} \mathrm{C}$, and the $\mathrm{pH}$ was not adjusted but had an initial value of 6.84. To eliminate any interference of coexisting inorganic composition, namely $\mathrm{CO}_{3}{ }^{2-}$ and $\mathrm{HCO}_{3}{ }^{-}$, on the radical-driven consumption of the target pollutants, the $\mathrm{pH}$ was adjusted to 4.5 .

\subsection{Determination of parameters}

Supernatant samples were taken periodically during the oxidation process and filtered with a $0.45 \mu \mathrm{m}$ filter membrane, followed by determining for these filtered samples their colours, biological oxygen demand (BOD), chemical oxygen demand (COD), and the concentrations of various compounds including TOC, PCs, cyanide, and SS. The amounts of total organic carbon (TOC) and inorganic carbon (IC) were determined by using

Table 1 Characteristics of the sample

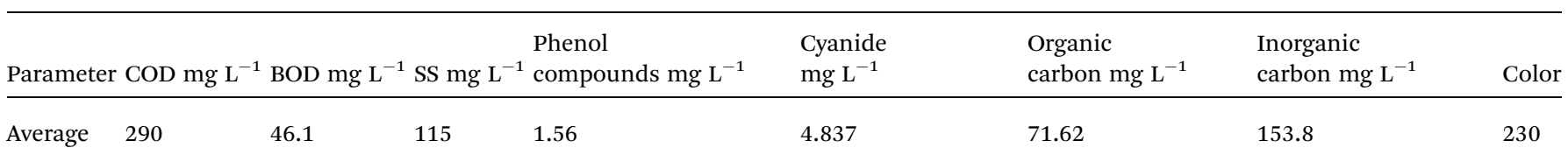


a TOC-VCPH analyzer (TOC-VCPH, Shimadzu Corporation, Kyoto, Japan). The concentration of PCs was measured by applying the Chinese national standard analysis method (the 4aminoantipyrine spectrophotometric method, HJ825-2017). The concentration of cyanide was determined by applying the colorimetric method after distillation. ${ }^{23}$ The color was determinded by the method of dilution multiple, and the SSs was measured by gravimetric method. The $\mathrm{pH}$ was measured using a portable $\mathrm{pH}$ meter (Mettler Toledo FE-20, Shanghai Miqingke Industrial Co. Ltd., China). The concentration of $\mathrm{SO}_{4}{ }^{2-}$ was measured using the barium sulfate precipitation method. Here, TOC was used because it is more accurate than the COD for determining the change in the concentration of total organics. The TOC was determined using eqn (4).

$$
\mathrm{TOC}=\mathrm{TC}-\mathrm{IC}
$$

In this equation, IC and TC are the concentrations of the compounds that can release $\mathrm{CO}_{2}$ at $150{ }^{\circ} \mathrm{C}$ and $900{ }^{\circ} \mathrm{C}$, respectively.

At the end of the experiment, the excess ZVI was separated from the suspensions by using a magnet. Then the samples were collected and analysed by performing GC/MS after being extracted by $\mathrm{CH}_{2} \mathrm{Cl}_{2}$ three times and then concentrated to $1 \mathrm{~mL}$. And another sample not subjected to the radical reaction was analysed as a control using the same method. All analytical measurements were taken in triplicate. A Trace 2000 gas chromatographer connected to a Thermo $\mathrm{DSQ}^{\mathrm{TM}}$ (dual-stage quadrupole) mass spectrometer (DSQII, Thermo, USA) with a DB-5 column $(30 \mathrm{~m} \times 0.25 \mathrm{~mm} \times 0.25 \mu \mathrm{m})$ was used for identifying the intermediate products. For this analysis, the carrier gas used was ultrapure helium (flowing at a rate of 1.0 $\mathrm{mL} \min ^{-1}$ ) - and the column temperature was set to $100{ }^{\circ} \mathrm{C}$, held at this temperature for $1 \mathrm{~min}$, then increased at a rate of $10{ }^{\circ} \mathrm{C} \mathrm{min}$ min $^{-1}$ until a temperature of $280{ }^{\circ} \mathrm{C}$ was reached, then increased at a rate of $5{ }^{\circ} \mathrm{C} \min ^{-1}$ until $310^{\circ} \mathrm{C}$ was reached, and held at this temperature for $2 \mathrm{~min}$. The injector and interface temperatures were set at 300 and $280{ }^{\circ} \mathrm{C}$, respectively. Full scan mode $(m / z=50-600)$ was used.

\section{Results and discussion}

\subsection{Dependence of the removal of organics on persulfate dosage}

The removal efficiencies for various mass concentration ratios are shown in Fig. 1. A clear increase in TOC removal efficiency was observed with the increasement of the persulfate dosage (Fig. 1b). As depicted, a 49.6\% TOC removal efficiency was obtained with a COD $/ \mathrm{S}_{2} \mathrm{O}_{8}{ }^{2-}$ ratio of $1: 4$, almost two times higher than that with a ratio of $1: 2$. With further increases in the persulfate dosage, the rate of increase in the removal efficiency declined and eventually the efficiency leveled off, especially after a $\mathrm{COD} / \mathrm{S}_{2} \mathrm{O}_{8}{ }^{2-}$ ratio of $1: 6$, though the maximum efficiency peaked at $58.5 \%$ when the $\mathrm{COD} / \mathrm{S}_{2} \mathrm{O}_{8}{ }^{2-}$ ratio reached $1: 10$. When pollutant removal efficiency and dosage economy
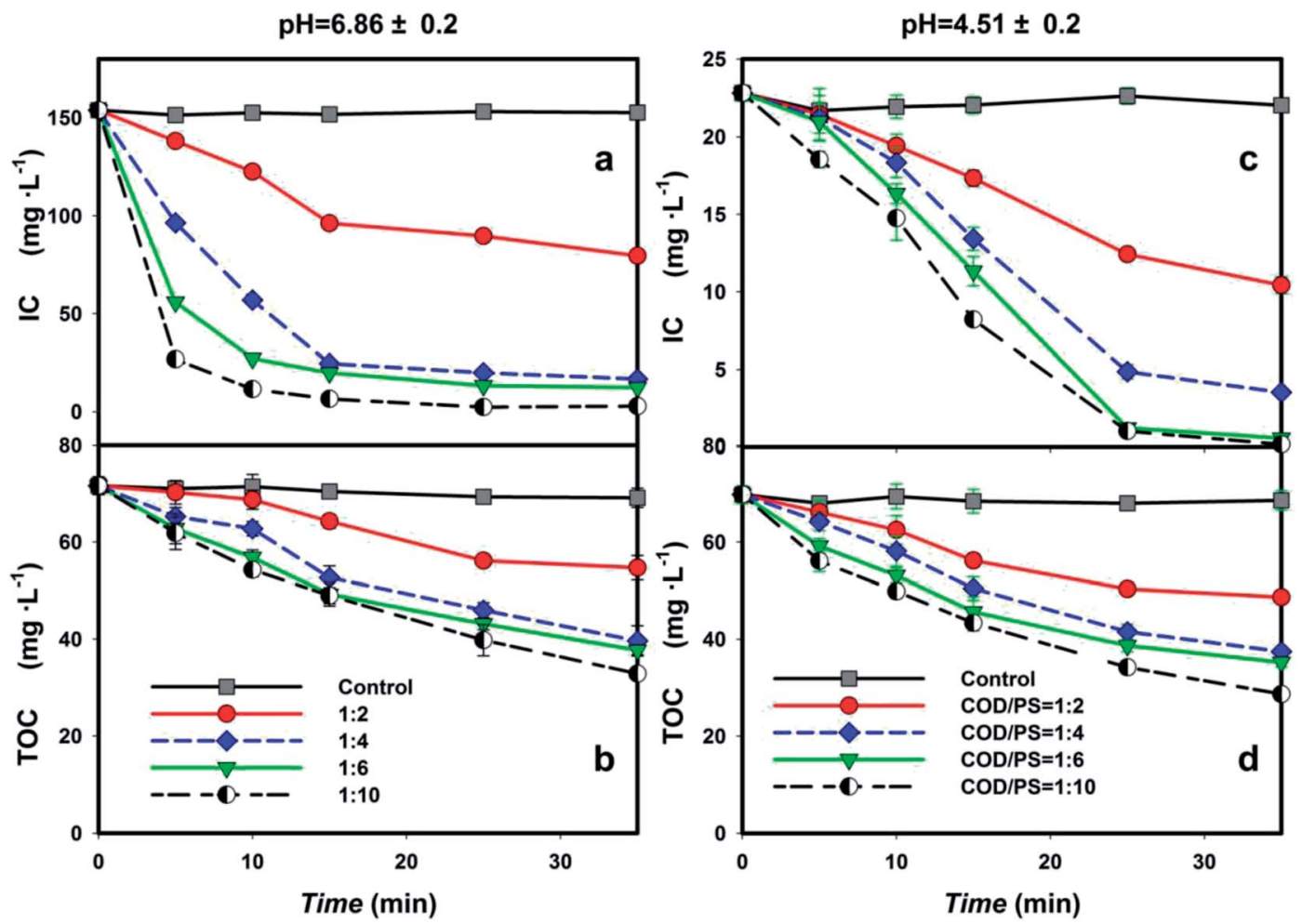

Fig. 1 TOC values at various reaction time points and for various COD-to-PS mass concentration ratios for (a) and (b) for IC and TOC concentration for $\mathrm{pH}_{\text {initial }}=6.8$, (c) and (d) for IC and TOC concentration for $\mathrm{pH}_{\text {initial }}=4.5$. (Note: $[C O D]_{0}=290 \mathrm{mg} \mathrm{L}^{-1},[\mathrm{TC}]_{0}=153.8 \mathrm{mg} \mathrm{L}^{-1}$, $[\mathrm{TOC}]_{0}=71.62 \mathrm{mg} \mathrm{L}^{-1}$, temperature, $25^{\circ} \mathrm{C}$.) 
of persulfate were taken into account, the most suitable mass concentration ratio of $\mathrm{COD} / \mathrm{Na}_{2} \mathrm{~S}_{2} \mathrm{O}_{8}$ was considered to be $1: 6$. At this ratio, the final TOC concentration after 35 min was $35 \mathrm{mg} \mathrm{\textrm {L } ^ { - 1 }}$ (corresponding to a $51 \%$ removal efficiency). The decline in removal efficiency at high persulfate dosage can be attributed to the more complicated side reaction that involved the consumption of $\mathrm{SO}_{4}{ }^{-\cdot}$ and PS by the coexisting compounds in the BECW ${ }^{24}$ which will be elaborated upon later.

Note that the IC removal rates for the above four ratios were $61.8 \%, 89.1 \%, 92 \%$, and $98.1 \%$, respectively, much higher than the TOC removal rates (Fig. 1a). The difference was due to the consumption of $\mathrm{SO}_{4}{ }^{-}$by the chain reaction between the radicals and inorganic compounds such as $\mathrm{HCO}_{3}{ }^{-}, \mathrm{CO}_{3}{ }^{2-}, \mathrm{CN}^{-}$, and $\mathrm{SCN}^{-}$in the $\mathrm{BECW},{ }^{21}$ which can occur immediately in the samples; ${ }^{24,25}$ this reaction generated another radical of $\mathrm{CO}_{3}{ }^{-}$. with a scarce capacity to remove organic matter. ${ }^{26}$ To eliminate any interference by coexisting inorganic components, namely $\mathrm{CO}_{3}{ }^{2-}$ and $\mathrm{HCO}_{3}{ }^{-}$, on the radical-driven consumption of target pollutants, the $\mathrm{pH}$ was adjusted to 4.5 . When introducing this condition, the amount of IC removed by $\mathrm{SO}_{4}{ }^{-\cdot}$ in the acidic solution dramatically declined (Fig. 1c). Based on this, the targeting of the heterocyclic organics by the sulfate radical was improved as demonstrated by the higher removal of TOC. For $\mathrm{COD} / \mathrm{S}_{2} \mathrm{O}_{8}{ }^{2-}$ ratios of $1: 2,1: 4,1: 6$, and $1: 10$, the TOC removal rates were $34.63 \%, 55.86 \%, 59.02 \%$, and $63.08 \%$, respectively, $2.73-9.00 \%$ higher than the TOC removal rates in the solution with a neutral $\mathrm{pH}$ value (Fig. 1d). In this sense, acidifying the solution before carrying out the radical reaction was essential for obtaining a high TOC removal efficiency.

Finally, the accelerated declines of both the TOC and IC concentrations after 10 minutes of reaction are worthy of attention. These declines may have resulted from a synergistic effect of the radical oxidation of the complex components in BECW by the addition of PS and flocculation sedimentation of suspended particles by the accumulation of generated $\mathrm{Fe}^{3+}$. While in the actual wastewater, the individual roles of the two

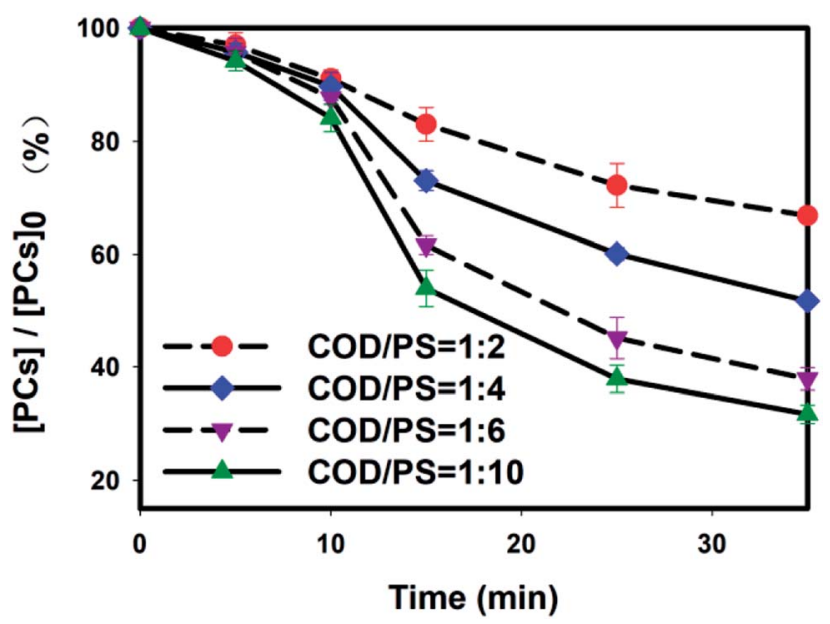

Fig. 2 Time course profiles of PC concentration, resulting from PS/ZVI oxidation in EBCW, for various COD-to-PS mass concentration ratios. (Note: $[C O D]_{0}=290 \mathrm{mg} \mathrm{L}^{-1},[P C s]_{0}=1.56 \mathrm{mg} \mathrm{L}^{-1}$, temperature, $25^{\circ} \mathrm{C}$, $\mathrm{pH}_{\text {initial }}=6.8$.) factors were difficult to distinguish, the approximate time when iron began to function as a flocculant was noticed. As observed, small flocs appeared at five minutes of the reaction. Then these flocs grew slowly and began to settle from 10 minutes onwards. This change was in agreement with the bigger change in the concentration of the organics from 10 to 15 minutes than that within the first 5 minutes.

\subsection{Phenol compound (PC) removal in BECW}

Phenol compounds constitute an important component of coking wastewater, but are highly toxic and worth treating. Though a removal efficiency of $98 \%$ was obtained during biological treatment, the residual phenol concentration in the BECW was $1.56 \mathrm{mg} \mathrm{L}^{-1}$, still greater than the national standard of $0.3 \mathrm{mg} \mathrm{L}^{-1}$. As shown in Fig. 2, for each concentration set, the PC concentration decreased modestly, by less than $20 \%$, within the first 10 minutes. These modest decreases can be explained by the $\mathrm{SO}_{4}{ }^{-}$being relatively less activated in the solution as a result of the limited $\mathrm{Fe}^{2+}$ release by the slow reaction of solid ZVI. $^{27}$ After the first ten minutes, a clear decrease of PC concentration was obtained in each case, and the rate of decrease was positively associated with the persulfate dosage. As a result, $35.6 \%, 48.3 \%$ and $62.1 \%$ of the PCs were removed when the mass ratios of the COD to PS were $1: 2,1: 4$ and $1: 6$, respectively. However, increasing the dosage further, to a mass ratio of $1: 10$, apparently did not yield an accelerated increase in the rate of PC removal, but an increase of only $6.3 \%$, less than

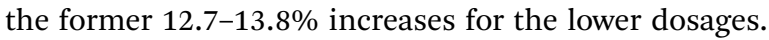

The moderate removal efficiency was attributed to the stable phenol structure with its good conjugation between the pi bond in the benzene ring and the lone pair electrons in the p orbitals of the hydroxyl, which made it more resistant to radical attack. ${ }^{28}$ In addition, the produced quinones, similar in having conjugated unsaturated ketones, were also stable structures and accumulated readily in the solution. This accumulation would also be expected to inhibit the PC oxidation process and lead to

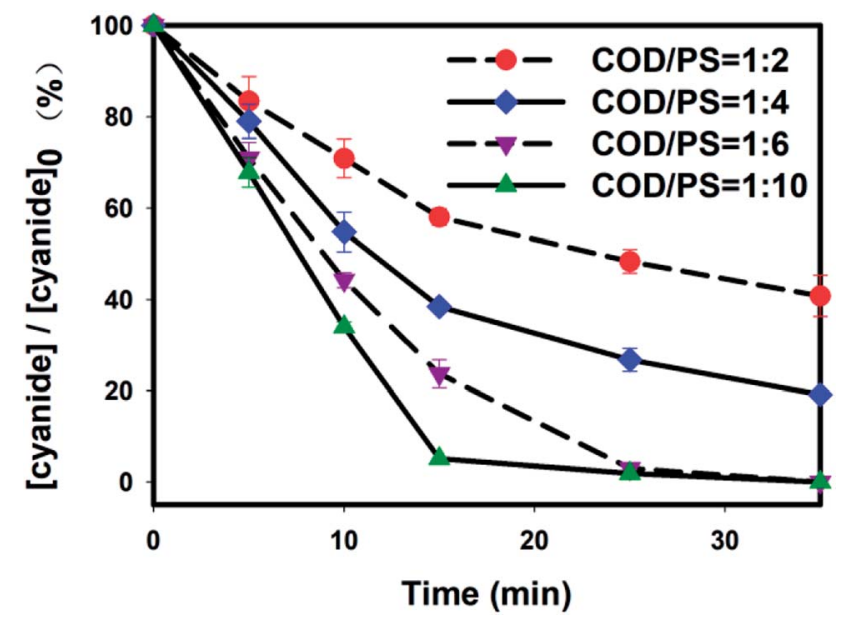

Fig. 3 Time course profiles of cyanide concentration, resulting from $\mathrm{PS} / \mathrm{ZVI}$ oxidation in EBCW, for various COD-to-PS mass concentration ratios. (Note: $[C O D]_{0}=290 \mathrm{mg} \mathrm{L}^{-1}$, [cyanide] ${ }_{0}=4.837 \mathrm{mg} \mathrm{L}^{-1}$, temperature, $25^{\circ} \mathrm{C}, \mathrm{pH}_{\text {initial }}=4.5$.) 

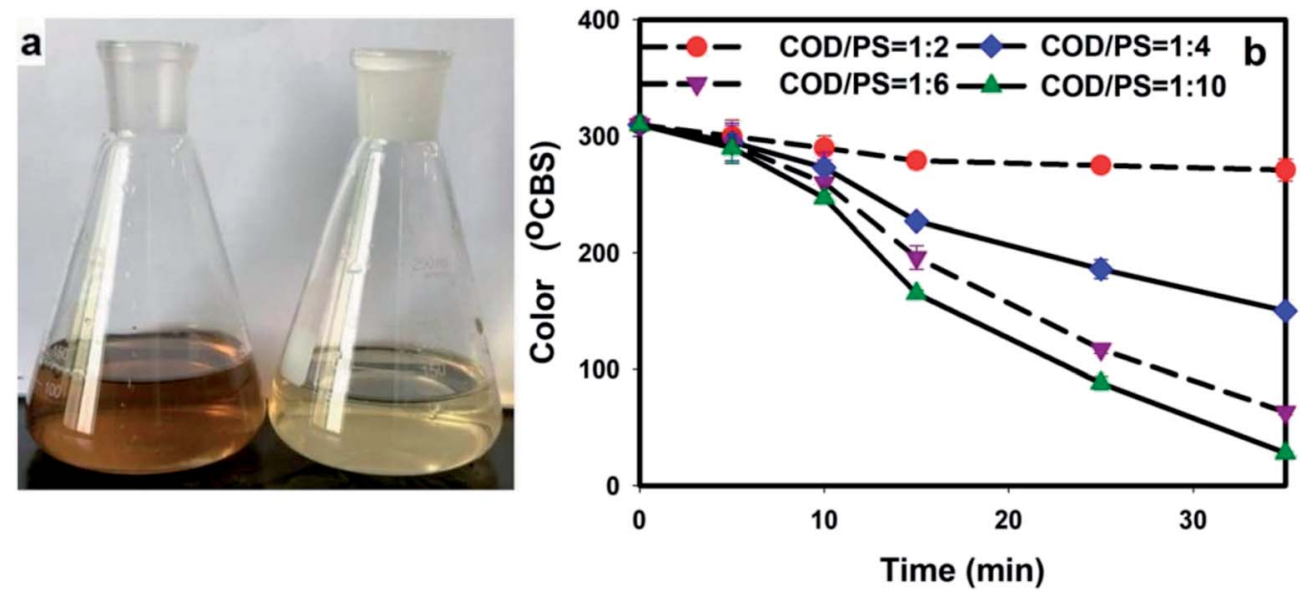

Fig. 4 (a) Color change before and after the radical oxidation. (b) Time course profiles of the color of the BECW for various COD-to-PS mass concentration ratios. (Note: $[\mathrm{PS}]_{0}=1740 \mathrm{mg} \mathrm{L}^{-1}$, color $_{\text {initial }}=310{ }^{\circ} \mathrm{CBS}, \mathrm{pH}_{\text {initial }}=4.5$, temperature, $25^{\circ} \mathrm{C}$.)

a low PC removal efficiency. Also, the rate constant of the PC reaction has been reported to be low (Table $\mathrm{S} 1 \dagger$ ).

\subsection{Cyanide removal resulting from persulfate oxidation}

As shown in Fig. 3, the cyanide removal rate was significantly affected by the PS/ZVI system. For each concentration set, the cyanide concentration sharply declined within $15 \mathrm{~min}$, indicating the strong oxidation capacity of the persulfate system. As depicted, the higher persulfate concentration ensured a rapid and complete removal of cyanide. The mass ratio of $1: 4$ yielded a nearly $81 \%$ of the cyanide having been removed, $42 \%$ greater than that resulting from the $1: 2$ mass ratio. For the mass concentration ratios of $1: 6$ and $1: 10,99.9 \%$ of the cyanide was removed with within 15 minutes and 25 minutes, respectively. The rapid decline of cyanide has been reported to be due to not only the radical reaction, but also to oxidation by $\mathrm{S}_{2} \mathrm{O}_{8}{ }^{2-}$ ions, which have a high oxidation potential of $2.01 \mathrm{eV}$. And the reaction between $\mathrm{S}_{2} \mathrm{O}_{8}{ }^{2-}$ and cyanides has been confirmed in the literature by Guo. ${ }^{29}$

Another radical reaction was more likely to have occurred during or even dominated the cyanide removal, since up to $4700 \mathrm{mg} \mathrm{L}^{-1}$ of $\mathrm{Cl}^{-}$was detected in the BECW (Table S2 $\dagger$ ). Lei recorded a chain reaction of $\mathrm{Cl}^{-}$with sulfate radical that produced another radical, namely $\mathrm{Cl}^{\circ}$. Thus, given the high concentration of $\mathrm{Cl}^{-}$in the solution, the generated $\mathrm{Cl}^{*}$ can make a great contribution to the cyanide removal. ${ }^{30}$ Furthermore, reaction between the sulfate radicals and the organics could generate $\mathrm{H}^{+}$and further improve chlorate generation. ${ }^{24}$ And released $\mathrm{H}_{2} \mathrm{OCl}^{*}$ and $\mathrm{Cl}^{*}$ can then play a positive role in the cyanide oxidation reaction.

\subsection{Change of colour in BECW}

Fig. 4 shows the change in colour during the oxidation of the BECW by the PS/ZVI system. As depicted, a clear change from dark brown to light yellow was observed (Fig. 4a) after the radical reaction, and SS precipitation resulted from the application of persulfate. Clearly, the more sulfate radicals produced, the greater was the extent of color removal as confirmed by the colour changes under different mass ratios (Fig. 4b). As shown in the figure, the colour change during the first five minutes was almost independent of persulfate dosage. Then, after 5 minutes, the greater dosage resulted in greater declines in color intensity. A similar rapid decline in the intensity of the color of the solution was also observed for organics after 10 minutes. This decline can be attributed to the predominantly occurring iron flocculation. At the end of the $35 \mathrm{~min}$ reaction, $12.4 \%$, $51.5 \%, 79.6 \%$, and $91.0 \%$ of the colour was removed for mass ratios of $1: 2,1: 4,1: 6$, and $1: 10$, respectively.

The colour of the coking wastewater can be attributed to large amounts of compounds including complex compounds formed by the residual ferric or cupric ion and cyanide or sulfur cyanide and chromogenic organics. The former can be eliminated by applying the cyanide removal method mentioned in Section 3.3, while removal of the latter was far more complicated. Preasphaltene, the primary product from dry distillation of coal during the coking process, was reported to be a typical chromogen and could be present in the BECW. ${ }^{31}$ Azo dyes can be formed during the coal processing. ${ }^{32}$ This formation may

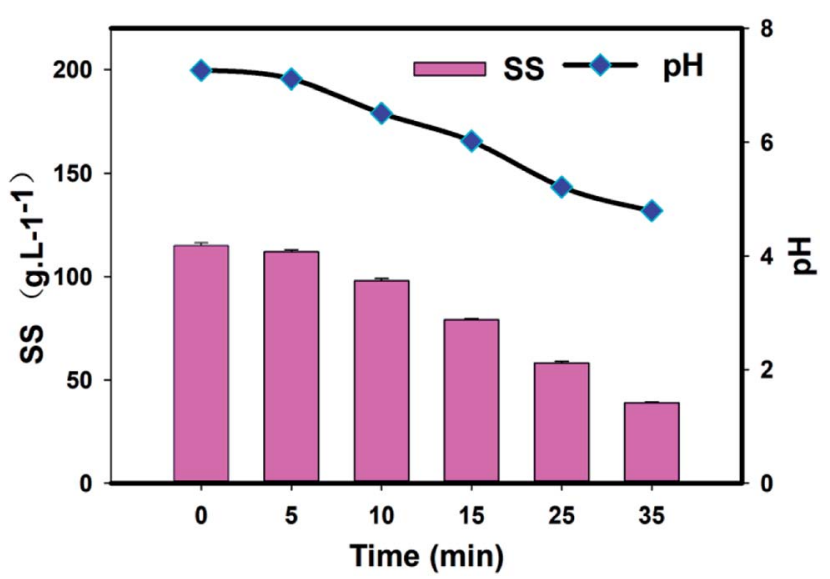

Fig. 5 The time course profiles of $\mathrm{SS}$ and $\mathrm{pH}$ of the EBCW. (Note: [PS] $=1740 \mathrm{mg} \mathrm{L}^{-1},[\mathrm{SS}]_{0}=115 \mathrm{mg} \mathrm{L}^{-1}, \mathrm{pH}_{\text {initial }}=6.8$, temperature, $25^{\circ} \mathrm{C}$.) 

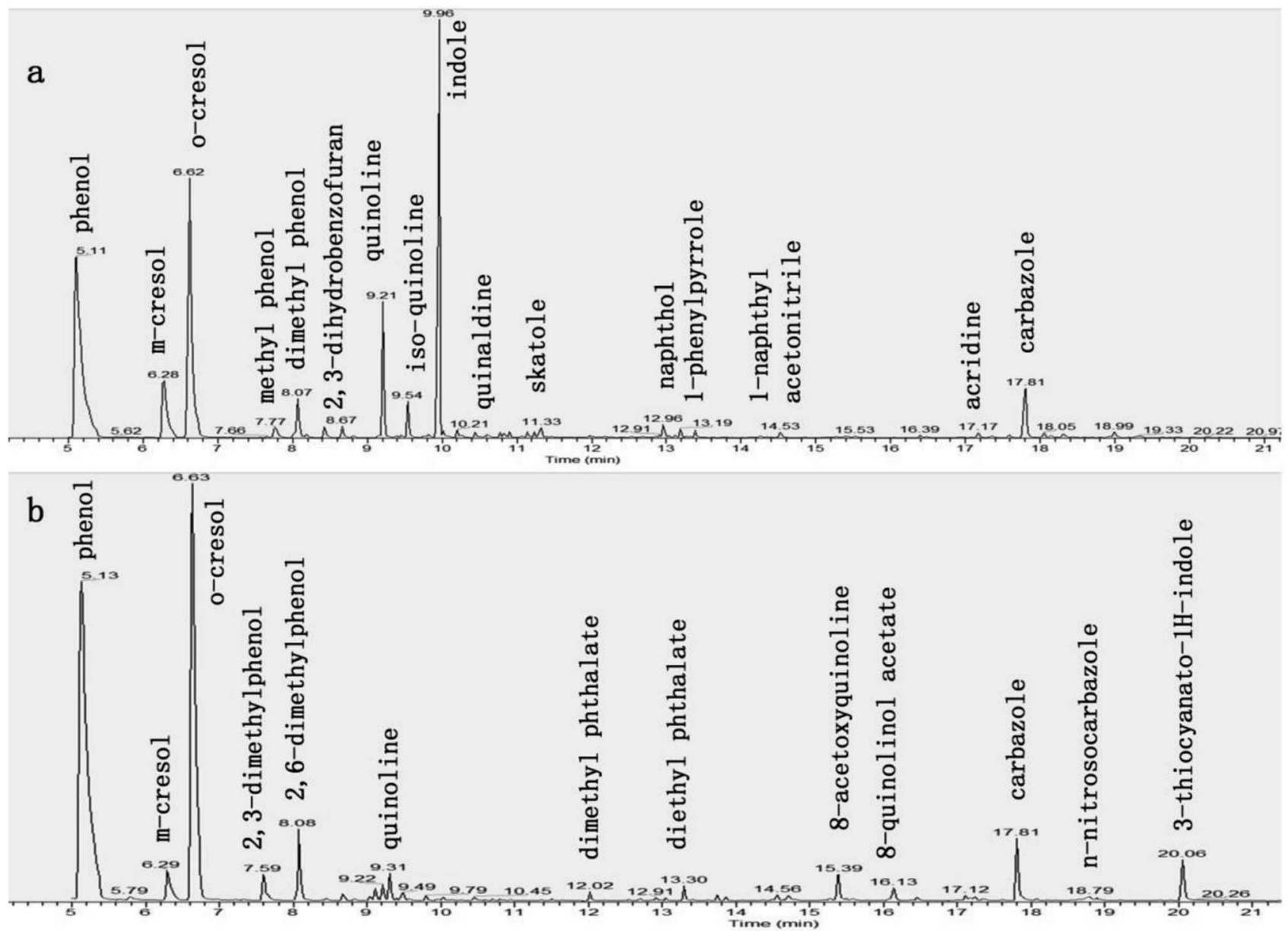

Fig. 6 Compositions of the EBCW, (a) for the sample before radical oxidation, (b) for the sample after 35 min oxidation reaction.

lead to an accumulation of chromogens in coking wastewater. Besides, many chromogenic groups such as the carboxyl $(-\mathrm{COOH})$ group and those groups containing the $\mathrm{C}=\mathrm{C}$ or $\mathrm{C}=\mathrm{O}$ double bond were in the complicated compounds including butyronitrile, amine, azo-heterocyclic compounds, polycyclic aromatic hydrocarbon (PAH), ketones, etc. ${ }^{33}$ These groups can absorb ultraviolet and visible-light wavelengths with a high coefficient and complete transition between energy levels, which can darken the colour. Furthermore, the rich auxochromic groups $\left(-\mathrm{NH}_{2},-\mathrm{OH},-\mathrm{OR},-\mathrm{SR},-\mathrm{X}\right.$, et al.) can also lead to increases in colour intensity.

And due to the low biodegradability of the mentioned compounds, large amounts of the chromogenic compounds were retained in the BECW and made it dark brown. Sulfate radicals can oxidize and decompose the chromogenic group of organics, further changing their structure and reducing the intensity of the colour. ${ }^{34,35}$ Huang $^{36}$ confirmed the destruction of the azo bond $(-\mathrm{N}=\mathrm{N}-)$ and the decomposition of the naphthalene ring to $\mathrm{CO}_{2}$ and $\mathrm{H}_{2} \mathrm{O}$ in orange $\mathrm{G}$ by sulfate radical attack. Methylene blue, with moderate reduction ability and strong polarity, was reported to be decolorized quickly by the sulfate radical. ${ }^{34}$ Another strong piece of evidence for the decolorization of the sulfate radical was the high efficiency of the removal of rhodamine $B$ by sulfate radical oxidation, of note since rhodamine $\mathrm{B}$ includes $\mathrm{C}=\mathrm{O}$ and $-\mathrm{NH}_{2}$ groups in its structure $^{35}$ (Table S3†). Consequently, it was the strong oxidation by the sulfate radical that eliminated the chromogenic groups and led to the significant change in colour.

\subsection{Suspended solid (SS) removal in BECW}

Fig. 5 shows the SS removal characteristics in the solution. Due to the slow release rate of $\mathrm{Fe}^{2+}$ into the reaction system, the concentrations of sulfate radicals and $\mathrm{Fe}^{3+}$ ions were relatively low at the initial stage, before 5 minutes for instance. Then the SS concentration slightly changed. As shown, the SS concentration began to decrease rapidly as the solution became turbid and small floccules appeared after about 5 minutes. There was an approximately $13.3 \%$ reduction in the SS concentration over the first 10 minutes, which was most likely due to the ever-growing flocs with the greater $\mathrm{Fe}^{2+}$ release. This downward trend continued until the end of the test, when the SS concentration eventually fell below $150 \mathrm{mg} \mathrm{L}^{-1}$, with a $61 \%$ removal efficiency. Corresponding to the SS removal, the $\mathrm{pH}$ was observed to decline from the initial 7.0 value to 4.8 .

The sudden increase in SS removal from 5 min onwards can be explained by the generation and accumulation of $\mathrm{Fe}^{3+}$ 

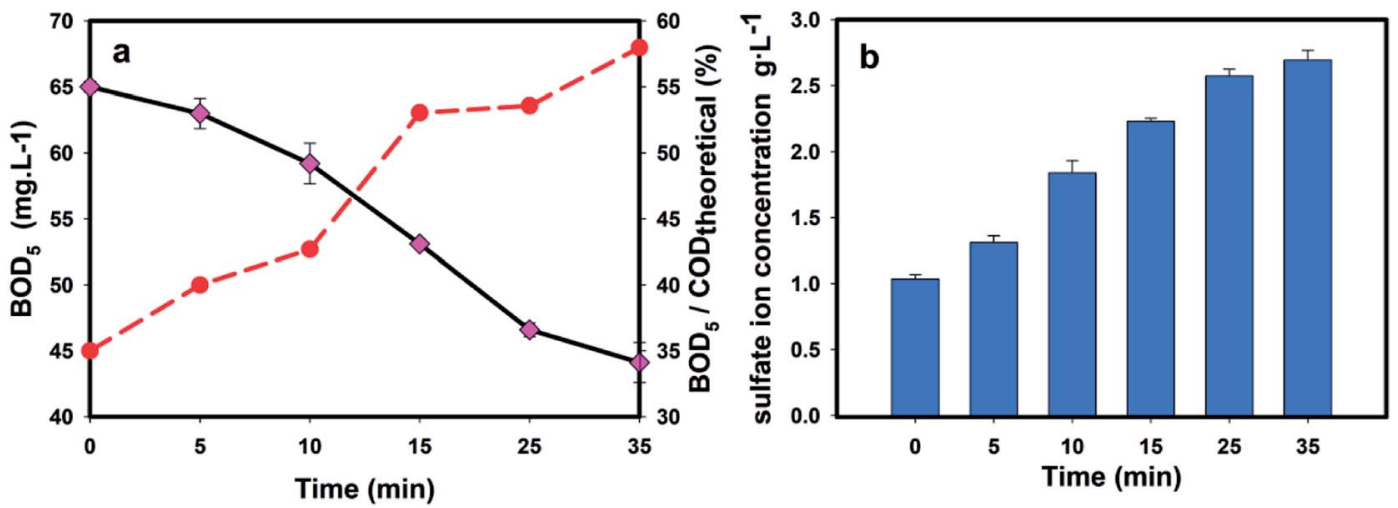

Fig. 7 The time course profiles of (a) the biodegradability and (b) $\mathrm{SO}_{4}{ }^{2-}$ concentration of the EBCW solution.

in the solution as the radical reaction proceeded. Further evidence for this explanation was the near simultaneous increase in the concentration of $\mathrm{Fe}^{3+}$ with the decrease in the $\mathrm{SS}$ concentration. The produced $\mathrm{Fe}^{3+}$ has been shown to be an active coagulant precursor with high binding affinity and is commonly used in drinking and wastewater treatment to precipitate organic and inorganic colloids. ${ }^{37-39}$ And it can bind tightly with negatively charged organic particles to remove the SS by flocculation and precipitation. It is noteworthy that accompanying the radical oxidation and ferric salt flocculation, a furl mechanism towards the large molecules was likely to occur, which would have further enhanced the SS removal efficiency.

\subsection{Composition and biodegradability change in BECW}

The change in the composition of BECW as a result of the persulfate oxidation was analyzed by acquiring GC-MS data of samples before and after the oxidation, as shown in Fig. 6 . These spectra showed distinct differences between the diversities of these two samples. Most NHCs, including pyridine, quinoline, isoquinoline, indole, carbazole and their derivatives, were removed to one extent or another as a result of the oxidation. For example, the indole completely disappeared in 25 minutes of the reaction; in contrast carbazole, with its balanced and stable structure, remained in the solution. We also observed a partial removal of PCs, including phenol and naphthol, which was in accordance with the change in the PC characteristics as described above in Section 3.2. Note that the concentration of $o$-cresol increased, which can be explained by a partial conversion of phenol. While some organics (phenol, $m$ cresol, and carbazole) remained in the solution at the end of the $35 \mathrm{~min}$ reaction, the biodegradability of the solution was significantly enhanced.

Fig. 7 shows the time profile of the $\mathrm{SO}_{4}{ }^{2-}$ and $\mathrm{BOD}$ concentrations during the oxidation. The gradually increasing concentration of $\mathrm{SO}_{4}{ }^{2-}$ indicated that both the release of $\mathrm{SO}_{4}{ }^{-}$ and the radical reaction proceeded. And with the oxidation proceeding, the produced $\mathrm{SO}_{4}{ }^{2-}$ accumulated. Based on the initial concentration of $\mathrm{SO}_{4}{ }^{2-}$ (with $1130 \mathrm{mg} \mathrm{L}^{-1}$ ) and stoichiometric relationship of the conversion of $\mathrm{S}_{2} \mathrm{O}_{8}{ }^{2-}$ to $\mathrm{SO}_{4}{ }^{2-}$ (eqn (5)), more than $1260 \mathrm{mg} \mathrm{L}^{-1} \mathrm{SO}_{4}{ }^{2-}$ was produced, indicating $90 \%$ of the oxidants were activated as $\mathrm{SO}_{4}{ }^{-*}$, which ensured a high radical reaction rate.

$$
\left[\mathrm{SO}_{4}{ }^{2-}\right]_{\text {increase }}=\left(\left[\mathrm{S}_{2} \mathrm{O}_{8}{ }^{2-}\right]_{\text {initial }} / 238\right) \times 64 \times 2-\left[\mathrm{SO}_{4}{ }^{2-}\right]_{\text {initial }}
$$

And as a result of the radical oxidation, the BOD concentration sharply decreased, suggesting that the organics were removed. Conversely, a steady uptrend of the BOD/COD ratio was observed, indicating that more lower-toxicity structures were generated after the sulfate radical attack. As shown in Fig. 7 b, the biodegradability increased by $29 \%$ from 0.45 to 0.58 after the oxidation, indicating its great potential in the decomposition of organic compounds as well as in pretreatments before biological processes.

\section{Conclusions}

The proposed PS/ZVI system was proved to be feasible and effective at upgrading BECW, with a maximum removal efficiency of $58.5 \%, 68.4 \%, 61 \% 99.9 \%$ and $91.04 \%$ for TOC, PCs, SS, cyanide and colour, respectively. This significant removal was attributed to the combined effect of sulfate radical oxidation and iron flocculation. As demonstrated by the GC-MS and BOD/COD ratio analyses, the compositional diversity clearly declined and the biodegradability was significantly improved, further suggesting the great potential of the PS/ZVI system for actual wastewater with complex and refractory compounds. In conclusion, the persulfate-based oxidation process was safer than the Fenton reaction, whose $\mathrm{pH}$ needs to be adjusted to 3.0 and which has a danger of producing an explosion. Besides, the improved biodegradability by oxidation can enhance natural degradation of the residual organics in the discharged water.

\section{Conflicts of interest}

There are no conflicts to declare. 


\section{Acknowledgements}

This research was supported by the National Natural Science Foundation of China (NSFC, No. 51608345), and by the Key Research and Development (R\&D) Project of Shanxi Province (No. 201603D321012).

\section{References}

1 W. Zhang, C. Wei, C. Feng, B. Yan, N. Li, P. Peng and J. Fu, Sci. Total Environ., 2012, 432, 396-403.

2 D. Park, D. S. Lee, Y. M. Kim and J. M. Park, Bioresour. Technol., 2008, 99, 2092-2096.

3 P. Ning, H. J. Bart, Y. Jiang, A. D. Haan and C. Tien, Sep. Purif. Technol., 2005, 41, 133-139.

4 C. A. Papadimitriou, P. Samaras and G. P. Sakellaropoulos, Bioresour. Technol., 2009, 99, 31-37.

5 Z. Wang, J. Chen, F. Tian, P. Yang, X. Qiao and Z. Yao, Environ. Forensics, 2010, 11, 161-167.

6 J. Cheng, T. Yuan, Q. Wu, W. Zhao, H. Xie, Y. Ma, J. Ma and W. Wang, Water, Air, Soil Pollut., 2007, 183, 437-446.

7 X. Zhou, Y. Li and Y. Zhao, RSC Adv., 2014, 4, 15620-15629.

8 B. Salehiforouz, A. A. Malekirad, M. Abdollahi, K. Rahzani and S. Mostafalou, Health, 2014, 6, 1230-1236.

9 A. Eisentraeger, B. H. Hollert, A. Sagner, A. Tiehm and J. Neuwoehner, Environmental Toxicology \& Environ. Toxicol. Chem., 2010, 27, 1590-1596.

10 M. Jiang, Y. M. Li and G. W. Gu, Acta Sci. Circumstantiae, 2005, 25, 1253-1258.

11 R. Kumar and P. Pal, Chem. Eng. J., 2012, 210, 33-44.

12 M. Dehua, L. Cong, Z. Xiaobiao, L. Rui and C. Lujun, Environ. Sci. Pollut. Res., 2016, 23, 1-10.

13 Q. Wei, S. Qiao, B. Sun, H. Zou, J. F. Chen and L. Shao, RSC Adv., 2015, 5, 93386-93393.

14 T. Lei, W. T. Zhao, X. Huang and X. C. Wang, China Water Wastewater, 2010, 26, 100-103.

15 N. Zhang, G. F. Xue, P. Liu and L. N. Wang, Adv. Mater. Res., 2012, 573-574, 516-520.

16 B. Mundy, B. Kuhnel, G. Hunter, R. Jarnis, D. Funk, S. Walker, N. Burns, J. Drago, W. Nezgod and J. Huang, Ozone: Sci. Eng., 2018, 40, 266-274.

17 K. Xiao, K. Pei, H. Wang, W. Yu, S. Liang, J. Hu, H. Hou, B. Liu and J. Yang, Water Res., 2018, 140, 232-242.

18 J. Bolobajev, E. Kattel, M. Viisimaa, A. Goi, M. Trapido, T. Tenno and N. Dulova, Chem. Eng. J., 2014, 255, 8-13.
19 Y. Feng, C. Liao, H. Li, C. Liu and K. Shih, Environ. Technol., 2018, 39, 1-11.

20 D. Zhang, L. Wu, J. Yao, H. Herrmann and H. H. Richnow, Chem. Eng. J., 2018, 374, 111-118.

21 M. Nie, C. Yan, X. Xiong, X. Wen, X. Yang, Z. Lv and W. Dong, Chem. Eng. J., 2018, 348, 455-463.

22 Y.-d. Chen, S.-H. Ho, D. Wang, Z.-s. Wei, J.-S. Chang and N.-q. Ren, Bioresour. Technol., 2018, 247, 463-470.

23 APHA, AWWA, WEF, Standard Methods for the Examination of Water and Wastewater, APHA, Washington, DC, 22th edn, 2012.

24 H. V. Lutze, N. Kerlin and T. C. Schmidt, Water Res., 2015, 72, 349-360.

25 S. Wacławek, H. V. Lutze, K. Grübel, V. V. T. Padil, M. Černík and D. D. Dionysiou, Chem. Eng. J., 2017, 330, 44-62.

26 S. Canonica, T. Kohn, M. Mac, F. J. Real, J. Wirz and U. Gunten, Environ. Sci. Technol., 2005, 39, 9182-9188.

27 X. Wei, N. Gao, C. Li, D. Yang, S. Zhou and L. Lei, Chem. Eng. J., 2016, 285, 660-670.

28 S. D. Brinkevich, N. I. Ostrovskaya, M. E. Parkhach, S. N. Samovich and O. I. Shadyro, Free Radical Res., 2012, 46, 295-302.

29 T. Guo, C. Dang, S. Tian, Y. Wang, D. Cao, Y. Gong, S. Zhao, R. Mao, B. Yang and X. Zhao, Chem. Eng. J., 2018, 347, 535542.

30 Y. Lei, C. S. Chen, J. Ai, H. Lin, Y. H. Huang and H. Zhang, RSC Adv., 2015, 6, 866-871.

31 Z. Wang, L. Li, H. Shui, Z. Wang, X. Cui, S. Ren, Z. Lei and S. Kang, Fuel, 2011, 90, 305-311.

32 S. Y. Yang, P. Wang, X. Yang, L. A. Shan, W. Y. Zhang, X. T. Shao and R. Niu, J. Hazard. Mater., 2010, 179, 552-558.

33 C. Lin, X. Zhuo, X. Yu, M. Yuan and C. H. Wei, RSC Adv., 2015, 5, 43786-43797.

34 A. Ghauch and A. M. Tuqan, Chem. Eng. J., 2012, 183, 162171.

35 Y. Leng, W. Guo, X. Shi, Y. Li and L. Xing, Ind. Eng. Chem. Res., 2013, 52, 13607-13612.

36 T. Huang, K. Zhang, Y. Qian, C. Fang and J. Chena, Environ. Sci. Pollut. Res., 2018, 25, 1-8.

37 H. Tang, J. P. Sha, Y. L. Ou and X. Zhao, Appl. Mech. Mater., 2015, 700, 426-430.

38 J. Y. Bottero and J. L. Bersillon, Adv. Chem., 1988, 425-442.

39 J. E. Greyor, C. J. Nokes and E. Fenton, Water Res., 1997, 31, 2949-2958. 